\title{
Teaching chemistry from a societal perspective*
}

\author{
Sylvia A. Ware \\ Director, Education and International Activities Division, American Chemical \\ Society, 1155 Sixteenth Street, NW, Washington, DC 20036, USA
}

\begin{abstract}
Chemistry and chemical technology contribute to the quality of life on this planet in many areas: health, nutrition, agriculture, transportation, materials and energy production, and industrial development. Chemistry is at its most useful to society when chemists and non-chemists with decision-making responsibilities work with mutual understanding to address the chemistry-related issues facing their communities. Thus, it would seem obvious that all who study chemistry should learn about the interactions of chemistry and society as an integral part of their classroom instruction. However, historically, the tendency worldwide has been to include societal content in chemistry courses only at the lower secondary level. This is changing. This paper explores instructional materials developed by the American Chemical Society that place chemistry in its societal context for high school and college students. This includes a discussion of green chemistry materials that introduce students to the concepts associated with developing environmentally benign processes and products.
\end{abstract}

\section{REFORM CONTEXT}

For more than 40 years, educators around the world have been engaged in the process of reforming science education, often beginning and ending with restructuring only the curriculum. This restructuring has taken place with two very different purposes, resulting in two distinct phases of reform. The first reform phase of the late 1950s and early 1960s focused on the development of secondary-level science courses that emphasized the nature of the science being studied, as a means of preparing students for a science career. (Most traditional introductory chemistry texts in use today are the products of the firstphase reforms.) For chemistry, it was assumed that the quickest way to make new chemists was to introduce inexperienced students to chemistry through the conceptual structure that had evolved over the previous 100 years. Science was viewed as "an objective, culture-free, value-neutral, intellectual pursuit explored by the most dispassionate of men (gender choice deliberate)" [1].

Many students, perhaps most, were uncomfortable with the high degree of abstraction in these courses and, where courses were elective, enrollments declined [2]. Chemistry was frequently described as "difficult", "boring", and "too abstract". Chemistry, the central and useful science, was viewed as "not relevant".

The second phase of reform has changed the audience for chemical information from the few who are headed for science careers to ALL students. Second-phase courses have varied a great deal in their content, but have tended toward a science/technology/society emphasis. The catch phrases are "science and technology literacy for all" and "science for citizenship" (c.f., UNESCO's Project 2000+). Here, the prime goal of teaching science, at least at the introductory levels, is to prepare students for life as citizens in a global community driven by science and technology. Given this goal, both the content and the pedagogical approach of second-phase courses have differed significantly from the first-phase programs.

*Lecture presented at the $8^{\text {th }}$ International Chemistry Conference in Africa ( $8^{\text {th }}$ ICCA), 30 July-4 August 2001, Dakar, Sénégal. Other presentations are published in this issue, pp. 1147-1223. 
But it is not only our attempt to reach the wider range of students that has altered the character of the second-phase courses. Over the past 50 years, we have shifted our principal model of student learning from a behaviorist viewpoint to a constructivist [3]. Following a behaviorist model of learning, the student is seen as an empty vessel into which knowledge can be poured by the teacher, given appropriate stimuli. The social constructivist model recognizes that students are not "empty vessels" but come to the classroom with minds full of previous knowledge, partial knowledge, misconceptions, naïve theories, and sheer "noise". According to this model, the student learns chemistry by reconciling new knowledge with this existing mélange of facts, opinions, understanding, and confusion. In a learning situation, there is a gradual shift toward understanding the accepted scientific explanations (see, for example, refs. 4-6). The constructivist model has tended to inform the development of the newer "science for all" courses, rather than the earlier "science for scientists" approach.

The assumption has been made in many quarters (not necessarily supported by research findings) that the science/technology/society approach to science curriculum development produces only courses of a lower intellectual level. These critics believe that science-bound students must be exposed to "structure of the discipline" courses as soon as possible, and that the two approaches are mutually exclusive. Hence, while a science and society approach may be commonly implemented on a worldwide basis at the lower-secondary level, such an approach is comparatively rare at the upper-secondary level, and almost nonexistent at the tertiary level. The remainder of this paper will discuss ACS efforts to teach chemistry from a societal context to both high school and undergraduate students in the United States, and why these efforts have been undertaken.

\section{CHEMISTRY, THE USEFUL SCIENCE}

Those of us who are chemists boast about chemistry being "the central science". By this, we mean that an understanding of chemistry is necessary to an understanding of the other sciences: biology, physics, geology, materials science, the environmental sciences, etc. We could just as easily mean that chemistry has been, and is, "central" to the quality of life that so many have come to enjoy over the past 50 years. Chemistry has been "central" in its utility, in the ubiquity of the products of chemistry in all facets of life, in all aspects of economic development. And for the future, chemists are uniquely qualified to contribute to the solution of many of the problems facing both developed and emerging nations, as both groups struggle, at different levels, with the issue of sustaining, environmentally benign economic growth. By virtue of their specialized knowledge, chemists have unique responsibilities to society. As stated in the ACS Chemists' Code of Conduct:

Chemists have a professional responsibility to serve the public interest and welfare and to further knowledge of science. Chemists should be concerned with the health and welfare of co-workers, consumers and the community.... Chemists should understand and anticipate the environmental consequences of their work. Chemists have a responsibility to avoid pollution and to protect the environment.

Clearly, an informed understanding of the interactions of chemistry and society are as important for chemists as for future politicians, journalists, lawyers, businessmen, and the voting public!

\section{CHEMISTRY, THE “DIFFICULT” SCIENCE}

It has been well demonstrated that many undergraduate chemistry students do not fully comprehend the concepts that they can, in fact, successfully apply, in algorithmic problem solving (see, for example, refs. 4, 7-10). These difficulties are highlighted in the disparity between student responses on computational tests versus their responses on related conceptual tests. One possible reason for the difficulty that many students have in understanding chemistry concepts may be the complexity of the levels at 
which we expect students to comprehend our discipline. Johnstone [11] has proposed three levels of understanding chemistry (and, more generally, other sciences):

- the macroscopic-i.e., the physical and chemical phenomena of chemistry;

- the submicroscopic or particulate-i.e., our models of chemical behavior on the atomic and molecular levels; and,

- the symbolic-i.e., the symbols, formulae, and mathematical relationships used to express chemical understanding.

To understand chemistry, students must move across these three forms of perception, yet, as pointed out by Gabel [4], at least in the United States, introductory chemistry instruction tends to focus on the more abstract of these levels of comprehension, the symbolic. She also indicates that teachers tend not to make explicit efforts to integrate the three levels, resulting in further confusion on the part of the students. It should be pointed out that the highly abstract nature of chemistry is itself a barrier to comprehension for many students; even at the undergraduate level not all students are functioning at the Piagetian level of "formal operations", at least not all of the time. Also, many students have great problems in visualizing the particulate models they are expected to understand. Here, the computer is proving a very useful tool for improving students' understanding of the particulate [12].

\section{RETHINKING THE CURRICULUM MODEL}

In the United States, the ACS has been involved in the development of chemistry for all courses for nearly 20 years, beginning in 1982 with the Chemistry in the Community (ChemCom) textbook. ChemCom [13] is a yearlong chemistry course for high school students that introduces the chemistry needed to understand important societal issues on a "need-to-know" basis. These issues include air and water quality, use of mineral resources, production of various sources of energy (petroleum and nuclear), industrial development, and food chemistry. ChemCom has been taught to over a million and a half students in the United States and continues to gain in popularity as it improves from edition to edition. There are also Russian, Japanese, and Spanish versions of the text. For the non-science major in college, ACS has also written Chemistry in Context [14]. This is a one-semester course that also uses societal issues to teach chemistry, but at a higher level.

Both of these courses share the following characteristics:

- the presentation of chemistry starting from a societal context (in this case, the U.S. cultural context);

- a focus on both the macroscopic and the particulate levels of comprehension of chemistry (enhanced by the use of computer animations, models, and graphics);

- $\quad$ an emphasis on inquiry-based laboratory activities;

- an introduction to ways of collecting and interpreting chemical data; and,

- the use, as needed, of the symbolic representations of chemistry.

When introducing societal content into a science course, it is possible to begin with the science as selected and sequenced in a "traditional" chemistry course, and to introduce the relevant societal content into the familiar science topics. Alternatively, it is possible to identify selected societal issues, and let them determine both what science content is to be taught and how it is to be sequenced. While either approach may be effective, the ACS materials were designed in the latter mode, as a means of first getting, and then keeping, the students' attention.

Students begin both courses realizing that chemistry is useful to society (and may also cause problems) because of the physical and chemical behavior of materials in both abiotic and biotic systems (the macroscopic facet of understanding chemistry). These behaviors can be explained through the use of the particulate theory of matter, which can also be used to predict and to modify the behavior of these materials. Every attempt is made to help students visualize the chemical phenomena that they are study- 
ing, an effort that has been enhanced in the fourth edition of ChemCom by use of the Internet, or a CD-ROM. The symbolic aspects of chemistry are not neglected, but are not given the initial emphasis found in more traditional courses. Again, when introduced, symbols, formulae, and mathematical manipulations are introduced through integration with the macroscopic and particulate levels of chemistry. (Note: the original developers of Chem Com did not consciously base the first edition of ChemCom on the three levels of chemistry. However, by the fourth edition it was clear that this was the direction in which the ChemCom project was developing.)

To illustrate this approach, the first unit of ChemCom on water begins with an exploration of why fish have been dying in a local river. In order to answer this question, the students need to learn a great deal of chemistry. They learn about the physical and chemical properties of water; the water cycle, the electrical nature of matter, ions and ionic compounds, molecular compounds, solutions and solubility, $\mathrm{pH}$, water purification, and water softening. Students are introduced to symbols, formulas, and equations as needed. They begin to interpret real-world graphical data, presented in a variety of forms. When they finally understand enough chemistry to determine why the fish died (and the book contains multiple scenarios), then they will decide who is responsible for correcting (and paying for) the problem.

Our students, as adult voters (or as politicians, journalists, lawyers, trade union officials, or future chemists), will be making decisions for their communities that involve applications of chemistry. Such decision-making is complex, multidisciplinary, and very different from the kinds of problem solving that take place in a traditional high school science class-or in any other class for that matter. If the educational process is to produce students who will become competent decision-makers within their society, then the students need to practice (or model) in the classroom, the kinds of decision-making in which they will participate as adults, even if only at a simplified level. Of course, both ChemCom and Chemistry in Context include many of the familiar exercises found in traditional chemistry courses, including laboratory activities and mathematical exercises.

\section{GREEN CHEMISTRY}

As stated earlier, chemists, by virtue of their specialized knowledge, have the responsibility of using their chemical knowledge in an environmentally responsible fashion. One of the more exciting aspects of modern chemistry has been the development of green chemistry. The term "green chemistry" is used to describe the design of chemical processes and products to reduce or eliminate the use and generation of hazardous substances, and to conserve materials and energy. The basic concept is to solve pollution problems by eliminating or minimizing pollution in the first instance. This is pollution prevention upstream at the molecular level. It is a concept that not only appeals to all students, but may even attract new students into chemistry careers, especially those contemplating careers in other sciences. It is a concept that appeals to industry in that green chemistry processes may reduce costs through a reduction in energy requirements; more complete utilization of the atoms in the reactants; and/or a reduction in the need for costly pollution controls, both for the reaction itself, and the management of any wastes generated.

The ACS Education Division has received two major grants from the U.S. Environmental Protection Agency to develop materials and disseminate information about green chemistry. Here, ACS has taken the approach of developing green chemistry materials to integrate into existing courses. Initially, the Division published a number of case studies in green chemistry for use in undergraduate chemistry courses [15]. These studies are based on the (U.S.) Presidential Green Chemistry Awards, which are given annually to both industry and academia in recognition of achievements in green chemistry research and development. ACS has also produced a video featuring some of the winners of these awards, and developed an annotated bibliography on green chemistry, searchable free over the Web (see www.acs.org/education/). In production at the moment are a number of "green" undergraduate laboratory activities, and thematic readers for undergraduates. Finally, together with the British and German chemical societies, ACS is currently working on green chemistry materials for secondary 
school students. These are designed to be infused into traditional upper secondary level courses, with some modifications, in all three countries.

The Green Chemistry Institute (GCI) became affiliated with the ACS in January 2001. The GCI promotes green chemistry research and education in the United States and internationally, especially to industry and government, and to academia at the undergraduate, graduate, and post-doctoral levels. They run conferences, workshops, and symposia, and coordinate a green chemistry network for information dissemination internationally.

Infusing green chemistry concepts into the undergraduate or graduate curriculum is relatively easy to do across chemistry subdisciplines, especially in organic, physical, or general chemistry programs. However, most faculty are not especially familiar with green chemistry at present, or convinced as to its importance. Thus, it is necessary to reach faculty with information on green chemistry, through workshops, seminars, and symposia. It is also important to reach future chemists, which the ACS is accomplishing through special programming activities for undergraduate students affiliated with ACS in student chapters across the nation. Workshops for students are held at ACS national and regional meetings; the student magazine, in Chemistry, features articles on green chemistry; and the ACS is initiating a mini-grant program to encourage the student chapters to work on green chemistry projects.

Anastas and Warner [16] have defined 12 principles of green chemistry that are being used by ACS and others to define the content of green chemistry instructional materials. These principles include a focus on the use of safer starting materials and solvents (both in terms of worker and environmental safety); the development of less toxic syntheses; the design of processes for energy efficiency; the use of renewable feedstocks where feasible; and the design of products, which, at the end of their life span, break down into innocuous degradation products.

One would expect that the future chemist who learns about green chemistry concepts during training would have a different mind-set from the student who does not. The industrial chemist will be looking not just at maximizing the yield of a process and minimizing its costs, but at the extent to which that process meets green chemistry criteria—and saves money in the process.

\section{CONCLUSIONS}

A well-designed effort to teach chemistry from a societal context can have the following impact. Through presenting chemistry, the useful science, as an evolving and socially responsible discipline, it may:

- Make chemistry knowledge accessible to a broad range of students.

- Help keep students' interest in the course.

- Force teachers to make efforts to integrate the three levels of comprehending chemistry, thus enhancing student learning. (Note that this still must be demonstrated by educational research.)

- Result in students staying longer in the science pipeline. (This is a demonstrable impact of ChemCom.)

- Through green chemistry, convince students majoring in other sciences that chemistry is both an intellectually exciting and ethically responsible career choice.

\section{REFERENCES}

1. S. A. Ware. Secondary School Science in Developing Countries: Status and Issues, World Bank, PHREE Document 92/53, World Bank, Washington, DC (1992).

2. P. Fensham. "Familiar but Different: Some Dilemmas and New Directions in Science Education". In: Development and Dilemmas in Science Education, P. Fensham (Ed.), The Falmer Press, London (1988).

3. J. D. Herron and S. C. Nurrenbern. J. Chem. Educ. 76 (10), 1354-1360 (1999). 
4. D. L. Gable. J. Chem. Educ. 76 (4), 548-54 (1999).

5. J. S. Kracjik. The Psychology of Learning Science, pp. 117-147, Lawrence Erlbaum, Hillsdale, NJ (1991).

6. R. Driver and V. Oldham. 1986. Studies in Science Education, 13, 105-122 (1986).

7. A. J. Wolfer and N. G. Lederman. "Introductory College Chemistry Students' Understanding of Stoichiometry: Connections between Conceptual and Computational Understandings and Instruction". Paper presented at the Annual Meeting of the National Association for Research in Science Teaching, New Orleans, April 2000.

8. D. L. Gable and D. M. Bunce. Handbook of Research on Science Teaching and Learning, pp. 301-326, Macmillan. New York (1994).

9. G. M. Bodner. J. Chem. Educ. 64, 385-388 (1991).

10. J. R. Staver. Sci. Educ. 73, 245-341 (1989).

11. A. H. Johnstone. J. Computer Assisted Learning 7, 75 (1991).

12. J. Kotz. Computer-Enhanced Chemistry (2001). See: http://www.oneonta.edu/ kotzjc/

13. ACS (American Chemical Society). Chemistry in the Community, $4^{\text {th }}$ ed., W. H. Freeman, New York (2001).

14. C. L. Stanitski, L. P. Eubanks, C. H. Middlecamp, W. H. Stratton. Chemistry in Context, $3^{\text {rd }}$ ed., McGraw-Hill Higher Education, Dubuque, IA (2000).

15. M. C. Cann and M. E. Connelly. Real-World Cases in Green Chemistry, American Chemical Society, Washington, DC (2000).

16. P. T. Anastas and J. C. Warner. Green Chemistry: Theory and Practice, p. 30, Oxford University Press, New York (1998). 